Article

\title{
Fast Pyrolysis of Sunflower Oil in the Presence of Microporous and Mesoporous Materials for Production of Bio-Oil
}

\author{
Aruzza M. M. Araújo ${ }^{1, *(\mathbb{B})}$, Gabriella S. M. Queiroz ${ }^{1}$, Danielle O. Maia ${ }^{2}$, \\ Amanda D. Gondim ${ }^{1}$ (D), Luiz D. Souza ${ }^{3}$, Valter J. Fernandes Jr. ${ }^{1}$ (D) and Antonio S. Araujo ${ }^{1}$ \\ 1 Institute of Chemistry, Federal University of Rio Grande do Norte, Natal 59078-970, RN, Brazil; \\ gabriella290593@hotmail.com (G.S.M.Q.); amandagondim.ufrn@gmail.com (A.D.G.); \\ valter.ufrn@gmail.com (V.J.F.J.); araujo.ufrn@gmail.com (A.S.A) \\ 2 Departament of Agricultural Engineering, Federal University of Maranhão, Chapadinha 65080-805, MA, \\ Brazil; dany_ufrn@yahoo.com.br \\ 3 Department of Chemistry, State University of Rio Grande do Norte, Mossoró 59610-210, RN, Brazil; \\ souzaluizdi@gmail.com \\ * Correspondence: aruzzamabel@gmail.com; Tel.: +55-84-99819-6979
}

Received: 30 April 2018; Accepted: 30 May 2018; Published: 28 June 2018

\begin{abstract}
The present work describes the study of micro (H-ZSM-5) and mesoporous (AL-MCM-41) structures, aiming at their application in the production of renewable fuels through the thermos-catalytic pyrolysis process both were synthesized hydrothermally and characterized by X-ray diffraction, thermal analysis, infrared spectroscopy, nitrogen adsorption, and surface acidity. The catalytic effect of the materials mentioned, as well as their mechanical mixtures in the proportions of H-ZSM-5 (75\% wt) and AL-MCM-41 (25\% wt); H-ZSM-5 (50\% wt) and AL-MCM-41 (50\% wt); H-ZSM-5 (25\% wt) and AL-MCM-41 (75\% wt) were used in the thermal and thermo-catalytic pyrolysis of sunflower oil. The products obtained in the presence of H-ZSM-5 (25\% wt) and AL-MCM-41(75\% wt) showed selectivity for the conversion of hydrocarbons between C11 and $\mathrm{C} 16$, which is near that of the petroleum-derived kerosene and diesel (>C16). On the other hand, the H-ZSM-5 (75\% wt) and AL-MCM-41 (25\% wt) material, in which the majoritarian catalyst is the microporous, with active sites and a higher surface acidity, indicates selectivity for light hydrocarbons (C5-C10), in the range of gasoline obtained by the conversion of mineral oil. The presence of catalysts (AL-MCM-41and H-ZSM-5) favors the deoxygenation of the pyrolysis products of sunflower oil by decarbonylation reaction.
\end{abstract}

Keywords: fast pyrolysis; sunflower oil; Al-MCM-41; H-ZSM-5; deoxygenation; renewable hydrocarbons

\section{Introduction}

The dependence on fossil fuels combined with the large increase in the emission of waste gases produced in the burning of oil causes serious environmental problems, as well as aggravates the hazards associated with the greenhouse effect and the ozone layer depletion [1,2]. Taking into account the growing increase in consumption, and these environmental problems, the need for new energy sources becomes clear.

Among the various possibilities of renewable fuels produced from biomass is the bio-oil, a mixture of organic compounds (alkanes, aromatic, phenol derivatives, ketones, esters, ethers, sugars, amines and alcohols) and smaller chain fatty acids generated from the pyrolysis of vegetable oil or animal fat, among other biomasses [3-5]. The pyrolysis is a complex process because the yields and compositions of end products of pyrolysis are dependent on biomass, temperature, 
residence time/temper heating rate, type of reactors, and others [6-8], and also dependent on conditions of the pyrolysis process yielding a distribution of solid, liquid, and gas products. However, the triacylglyceride pyrolysis, when performed at a temperature of around $500{ }^{\circ} \mathrm{C}$, the absence of oxygen and having a small residence time, favors the formation of liquid products ( 60 to $75 \%$ by weight) [9-11].

These pyrolysis products, mainly hydrocarbons, have properties very similar to those of gasoline, kerosene and/or petroleum diesel, which can be used directly in conventional compression ignition engines, which we call drop-in fuel [12,13]. Drop-in biofuels are hydrocarbon fuels compared to gasoline and diesel, which can be transported through the existing petroleum pipeline and are ready for vehicles to use without any modification to engines [14]. The presence of the catalyst in the pyrolysis process of triacylglyceride allows the reduction of temperature in process, increased percentage of hydrocarbons and oxygenated product reduction through decarboxylation and decarbonylation reaction.

Several studies have been used to evaluate the activity of catalysts in the thermo-catalytic pyrolysis and conversion of biomass to hydrocarbons, having indicated very promising results [8,9]. Some of the catalysts investigated for the obtainment of hydrocarbons were: bimetallic Ni- $\mathrm{Zn} / \mathrm{Al}_{2} \mathrm{O}_{3}$ [15], $\mathrm{Ni}_{2} \mathrm{P} / \mathrm{SiO}_{2}$ [16], $\mathrm{MgO}$ [17], Ga/H-ZSM-5 [18], Pt/MZ-5 [19] $\mathrm{Pt} / \mathrm{Al}_{2} \mathrm{O}_{3}$ and $\mathrm{Pd} / \mathrm{Al}_{2} \mathrm{O}_{3}$ [20], among others. Araújo [21] studied the application of the AlMCM-41 catalyst, with a $\mathrm{Si} / \mathrm{Al}$ ratio of 50, in the pyrolysis of sunflower oil through a batch tube reactor and the liquid products obtained were evaluated by acidity index, infrared spectrometry (FTIR) and gas chromatography coupled to a mass spectrometer (GC/MS). As a result, it was observed that the presence of the catalyst reduced the production of acid products, indicating an increased decarbonylation/decarboxylation, thereby improving the quality of the bio-oil obtained. Mâncio and colleagues [22] studied the influence of catalyst content on the physicochemical, yield and chemical composition (hydrocarbons and oxygenates) of organic liquid products (OLP) obtained by thermal-catalytic cracking of palm oil. The catalyst tested was the $\mathrm{Na}_{2} \mathrm{CO}_{3}$, which resulted in organic liquid products with a higher presence of hydrocarbons ranging from $\mathrm{C} 12$ to $\mathrm{C} 15$. This sum shows a tendency to increase with increasing catalyst content.

From the point of view of catalysis, recent studies point to greater selectivity of the diesel-like fraction when there is an increase in pore diameter. For catalysts with a smaller pore diameter, the selectivity is higher for the gasoline fraction [23,24].

The MCM-41, the main representative of a mesoporous family called M-41S, discovered by scientists at the Mobil Oil Research and Development Corporation [21,25], is a silicate obtained through the "liquid crystal support mechanism". Its porous system is formed by well-defined channels of shape and size, arranged hexagonally in space like a beehive, which is characterized by high surface area, hexagonal structure of one-dimensional mesopores with pore diameters ranging from 2 to $10 \mathrm{~nm}$, good thermal stability and moderate acidity.

Another studied structure is the MFI microporous zeolite type ZSM-5, which is considered a promising material for use in catalytic reactions and adsorption processes. However, the traditional synthesis of this material generates undesirable byproducts, mainly, with respect to the thermal decomposition of the structural template. This thermal decomposition, or calcination, generates a higher cost for the final product, besides promoting damage to the environment [26,27]. In view of the above, the ZSM- 5 type zeolite synthesis process was carried out in the absence of an organic template.

The oil chosen for this research was the sunflower, extracted from a flower of the same name and widely cultivated in the Brazilian cerrado and around the world. The seeds can generate $35-50 \%$ oil and yield $800 \mathrm{~L}$ of oil per hectare [28]. It has presented great potential for obtaining fractions of biofuels with carbonic chains similar to petroleum diesel, through processes such as pyrolysis.

In this sense, the objective of this work is to study the products of the thermo-catalytic pyrolysis of sunflower oil in the presence of the microporous catalyst Al-MCM-4, the mesoporous catalyst H-ZSM-5, and with their blends of the two catalysts. 
Obtaining biofuels from the pyrolysis of vegetable oils, such as sunflower oil, has recently become of great importance due to their renewable nature, wide availability, biodegradability and the possibility of including a new source, one that does not depend on fossil fuel, into the energy matrix [21].

\section{Results and Discussion}

\subsection{Characterization of the Catalysts Obtained}

As can be observed in Figure 1a, the X-ray diffractogram shows a topography characteristic of a one-dimensional hexagonal structure, of Al-MCM-41 type, as proposed by Beck and colleagues [25].
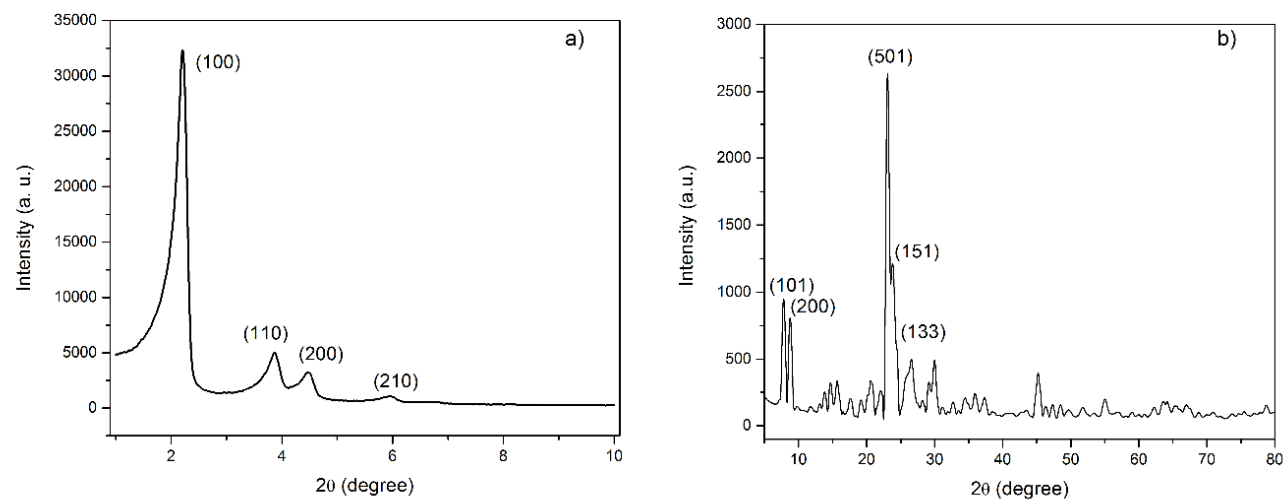

Figure 1. X-ray diffractogram of the ALMCM material (a); and HZSM5 (b).

The presence of four reflections, which are characteristic to plane diffraction, were identified. Their indices were [(100), (110), (200) and (210)]. According to the literature, these reflections are characteristic of the hexagonal arrangement of the material. The concept of crystallinity cannot be employed since its walls are amorphous silica. The absence of peaks at higher angles indicates that the material is not crystalline; however, it is known that there is an ordered hexagonal network, where the pore is surrounded by the other six, generating the reflections characteristic to MCM-41, which can also be observed by the high intensity of the first reflection $(100)[21,25,29,30]$.

From the X-ray diffractogram illustrated in Figure 1b, which represents the HZSM5 sample, an MFI crystalline structure can be observed with five characteristic reflections referring to the Miller indices [(101), (200), (501), (151) and (133)], of high intensity, similar to the standard proposed by IZA, and of satisfactory crystallinity. These confirm that the structure pertinent to ZSM- 5 zeolite was not altered due to the thermal treatments conducted. The similarity between the crystalline structures of the HZSM5 zeolites, synthesized in the absence of organic template, with the standard ZSM-5 demonstrates the efficiency of the synthesis methods applied. These are also in accordance with the diffractograms presented in the literature $[26,27,31,32]$.

This analysis was performed only on the ALMCM sample, since its route of synthesis has a structural template in the synthesis gel. This is contrary to what was proposed for the synthesis of the HZSM5 material.

The thermogravimetric curves (TG/DTG) of the synthesized mesoporous material are shown in Figure 2. According to data found in the literature [21,33], for materials of the ALMCM type in their non-calcined form, two main stages of mass loss are evidenced. The first stage corresponds to the desorption of physically adsorbed water and the second stage to the decomposition of the organic material (surfactant) from the pores of the material. Following these is a less significant mass loss due to the condensation of the silanol groups. 

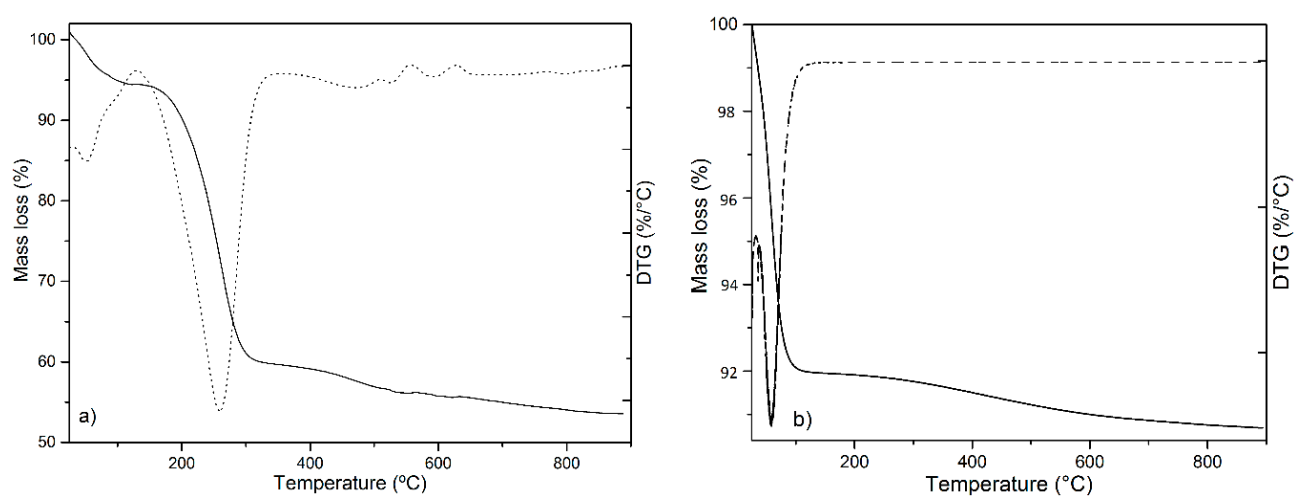

Figure 2. TG and DTG curves of the non-calcined ALMCM sample (a); calcined ALMCM sample (b).

As shown in Table 1, the first mass loss occurred in the temperature range of 50 to $127^{\circ} \mathrm{C}$. This is possibly attributed to the moisture the material was exposed to before the thermogravimetric analysis. Furthermore, since physically adsorbed water is inherent to silica-based materials, the material is very susceptible to humidity.

Table 1. Identification of temperature ranges and mass losses for the uncalcined ALMCM.

\begin{tabular}{ccccc}
\hline Sample & STAGES & Temperature Ranges $\left({ }^{\circ} \mathbf{C}\right)$ & Mass Losses $(\%)$ & Residues (\%) \\
\hline ALMCM & 1 & $50-127$ & 3.93 & \\
(Non-calcined) & 2 & $128-350$ & 34.82 & 58.3 \\
ALMCM & 1 & $351-653$ & 2.92 & \\
(Calcined) & 2 & $34-130$ & 4.88 & 95.2 \\
\hline
\end{tabular}

The temperature range of 128 to $350{ }^{\circ} \mathrm{C}$, which corresponds to the second mass loss, is characteristic of the removal of the $\mathrm{CTMA}^{+}$ions that are poorly bound to the surface of the material or located on the external walls of the silica.

In the temperature range of 351 to $653{ }^{\circ} \mathrm{C}$, the mass loss is only perceptible observing the derivative of the thermogravimetric curve. This variation of mass loss may be related to the aluminum impregnation in the ALMCM structure, which might interfere with the condensation of the silanol groups (Si-O-Si and Al-O-Si). It is important to point out that the bonds between silicon, oxygen and aluminum occur with different interactions [21].

In Table 1 and in the thermogravimetry curves shown in Figure 2b, it can be seen that the calcined ALMCM material, at the temperature of $450{ }^{\circ} \mathrm{C}$, presents a single mass loss event in the range of 34 to $130{ }^{\circ} \mathrm{C}$, with $4.88 \%$ loss. This is attributed to the water absorbed before the thermogravimetric analysis, since the mesoporous material is silica-based. The mesoporous material was free from an organic template [21,34].

Similarities were observed in the spectra for the calcined and non-calcined forms (Figure 3 and Table 2). This is due to the absorptions of Si-O-Si and Al-O-Si bonds occurring in the same spectral region, between 1300 and $1000 \mathrm{~cm}^{-1}$ [35]. This technique is particularly important because it allows for the identification, through the absorption bands, of the organic functional groups present in the template's structure, $\mathrm{CTMA}^{+}$, contained in the ALMCM channels in the non-calcined form. The disappearance of the band related to this functional group, for the calcined sample, shows that the organic material was successfully removed from the pores of the mesoporous molecular sieve [21]. 


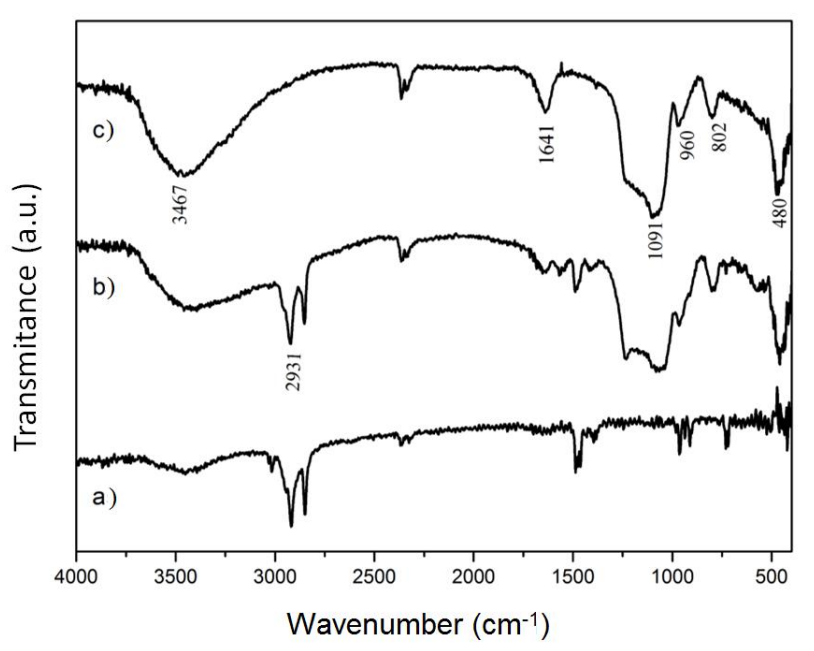

Figure 3. Infrared spectra of the mesoporous material ALMCM. (a) structural template-CTMAB; (b) non-calcined ALMCM; (c) calcined ALMCM.

Table 2. Data on the vibrational frequencies observed and their respective attributions made for the infrared spectra of ALMCM.

\begin{tabular}{cl}
\hline Wave Number $\left(\mathbf{c m}^{-\mathbf{1}}\right)$ & \multicolumn{1}{c}{ Attributed to } \\
\hline $\mathbf{3 7 5 0 - 2 9 5 0}$ & Internal and external hydroxyl groups in the mesoporous structure \\
$\mathbf{2 9 8 0 - 2 8 2 0}$ & Stretching between the C-H of the $\mathrm{CH}$ 2 and $\mathrm{CH}$ groups in the $\mathrm{CTMA}^{+}$ \\
$\mathbf{1 7 3 0 - 1 5 6 0}$ & Water adsorbed on the surface of the material \\
$\mathbf{1 5 1 0 - 1 4 5 0}$ & Deformations of the CTMA ${ }^{+}$ion \\
$\mathbf{1 2 6 0 - 1 2 1 5}$ & Si-O asymmetric stretching \\
$\mathbf{1 1 5 0 - 1 0 1 0}$ & Vibrations in the tetrahedra of the TOT bonds $(\mathrm{T}=\mathrm{Si} / \mathrm{Al})$ \\
$\mathbf{9 8 5 - 9 2 5}$ & Asymmetric stretching of the $\mathrm{CH}-\mathrm{N}+$ bond \\
$\mathbf{8 4 0 - 7 7 0}$ & Symmetric stretching of the T-O bonds $(\mathrm{T}=\mathrm{Si} / \mathrm{Al})$ \\
$\mathbf{4 9 5 - 4 2 0}$ & Asymmetric stretching of the T-O bonds $(\mathrm{T}=\mathrm{Si} / \mathrm{Al})$ \\
\hline
\end{tabular}

In the ALMCM spectra, a very wide band is observed in the region of $3467 \mathrm{~cm}^{-1}$. This belongs to possible silanol groups, as well as water adsorbed on the surface of the material. This calcined sample shows no absorption band in the $2931 \mathrm{~cm}^{-1}$ region. This is present in the spectra of the uncalcined sample and in the template, being attributed to the stretching between the $\mathrm{C}-\mathrm{H}$ of the $\mathrm{CH}_{2}$ and $\mathrm{CH}_{3}$ groups related to the surfactant $\left(\mathrm{CTMA}^{+)}\right.$molecules. The absence of this band allows for affirming that the organic material present in the pores was removed after the calcination step.

In the spectra of the uncalcined and calcined ALMCM samples, typical bands corresponding to the asymmetric stretching of the $\mathrm{Si}-\mathrm{O}$ bond are observed between $1245-1047 \mathrm{~cm}^{-1}$, as well as to the stretching of the $\mathrm{T}-\mathrm{O}$ bonds $\left(\mathrm{T}=\mathrm{Si}\right.$ or $\mathrm{Al}$ ) in the region of $802 \mathrm{~cm}^{-1}$, which are very common in silicates and aluminosilicates [21].

In both Figure 4 and Table 3, the spectrum of the HZSM5 zeolite can be observed. A wide and intense band is located at approximately $3435 \mathrm{~cm}^{-1}$; this, according to Silverstein and colleagues [36], refers to the axial deformation vibrations of the $\mathrm{OH}$ in the $\mathrm{SiOH}$ group, which occur in the region of 3700 to $3200 \mathrm{~cm}^{-1}$. The band observed in the region of $1641 \mathrm{~cm}^{-1}$ corresponds to the deformation vibrations of water molecules. The bands at 1224 and $1066 \mathrm{~cm}^{-1}$ represent the external and internal asymmetric stretching of the Si-O-Si siloxane groups. The band in the region of $788 \mathrm{~cm}^{-1}$ represents the symmetric stretching of the Si-O-Si siloxane groups $[25,29,36]$.

The internal flexions of the tetrahedrons correspond to the band seen at $457 \mathrm{~cm}^{-1}$, and the band referring to the length $545 \mathrm{~cm}^{-1}$ defines the presence of five-membered double rings pertaining to the three-dimensional porous structure of ZSM-5, as reported in the literature $[26,37,38]$. 
As can be observed in Table 3, the absence of bands characteristic of organic molds demonstrates the efficiency of the synthesis in the absence of a template, indicating that its MFI structure was possibly reached due to the action of the $\mathrm{Na}^{+}$ions as a structural template. This assumption has not been fully substantiated yet.

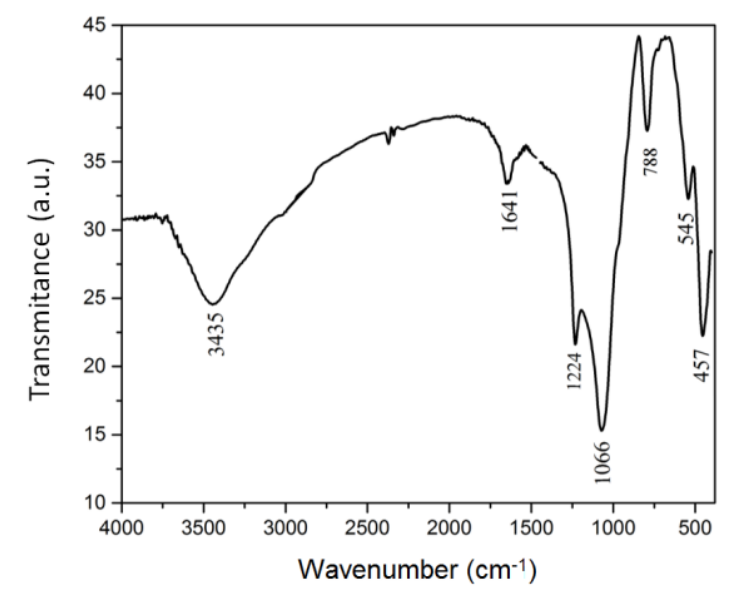

Figure 4. Infrared spectra of the mesoporous material HZSM5.

Table 3. Data on the vibrational frequencies observed and their respective attributions made for the infrared spectrum of HZSM5 zeolite.

\begin{tabular}{cl}
\hline Wave Number $\left(\mathrm{cm}^{-1}\right)$ & \multicolumn{1}{c}{ Attributed to } \\
\hline 3640 & Internal and external OH groups \\
$\mathbf{1 6 4 1}$ & Water adsorbed on the surface of the material \\
$\mathbf{1 0 6 6}$ & Internal tetrahedral asymmetric stretching of the $\mathrm{T}-\mathrm{O}(\mathrm{T}=\mathrm{Si}$ or $\mathrm{Al})$ \\
$\mathbf{4 5 7}$ & Flexion $(\mathrm{T}-\mathrm{O}, \mathrm{T}=\mathrm{Si}$ or $\mathrm{Al})$ \\
$\mathbf{7 8 8}$ & External tetrahedral symmetrical stretching \\
$\mathbf{5 4 5}$ & Polyhedrons present in the structure \\
\hline
\end{tabular}

Figure 5 shows results of the nitrogen adsorption/desorption isotherms consistent with those presented by the X-ray diffractograms. The ALMCM sample presents a type IV isotherm as shown in Figure 5a, and the occurrence of capillary condensation at relative pressures between 0.4 and 0.98 can be observed [21,25]. Because of the different saturation pressures for condensation (adsorption) and evaporation (desorption), a hysteresis is observed in the same figure, causing the adsorption and desorption isotherms to not coincide.
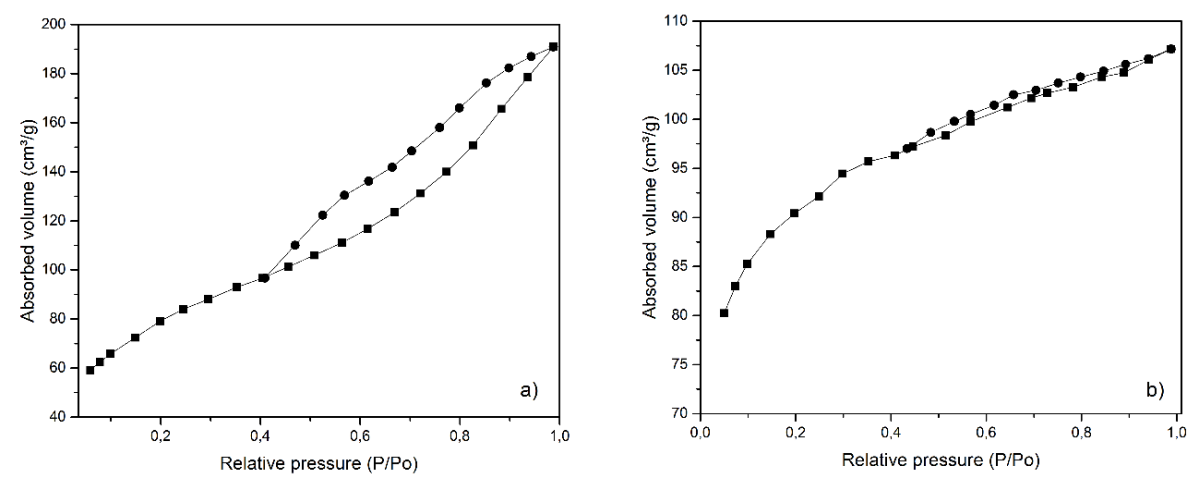

Figure 5. Nitrogen adsorption/desorption isotherms for the ALMCM (a) and HZSM5 (b). 
Also corroborating with the results of the XRD, the HZSM5 material in its protonated form showed a type I isotherm, which is characteristic of microporous materials, as shown in Figure $5 \mathrm{~b}$. However, since the limiting factor for monolayer formation in this material is strongly bound to the micropore volume in the region of 0.43 to $0.94 \mathrm{P} / \mathrm{P}_{0}$, the multilayer physical adsorption process associated with capillary condensation on the surface of the adsorbate is observed [39]. The structural properties obtained from the adsorption of $\mathrm{N}_{2}$ by the BET method are shown in Table 4 .

The similarities between the values of the physical properties of the samples prove the efficiency of the synthesis methods for both the ALMCM and the HZSM5 [21,26,40,41].

Table 4. Textural properties of the ALMCM and HZSM5 samples.

\begin{tabular}{|c|c|c|c|c|c|}
\hline Sample & $a_{0}{ }^{a}(n m)$ & $\mathrm{D}_{\mathrm{p}}^{\mathrm{b}}(\mathrm{nm})$ & $\mathrm{W}_{\mathrm{t}}^{\mathrm{c}}(\mathrm{nm})$ & $V_{p}^{d}\left(\mathrm{~cm}^{3} / g\right)$ & $S_{\text {BET }}$ e $\left(\mathrm{m}^{2} / \mathrm{g}\right)$ \\
\hline ALMCM & 4.77 & 3.10 & 1.67 & 0.38 & 824.5 \\
\hline HZSM5 & - & 1.80 & - & 0.23 & 286.8 \\
\hline
\end{tabular}

a Network parameter of the hexagonal arrangement, ${ }^{\mathrm{b}}$ pore diameter (by the BJH method in the adsorption step),

${ }^{c}$ wall thickness $\left(W_{t}=a_{0}-D_{p}\right){ }^{d}$ pore volume, ${ }^{e}$ specific surface area.

The acidity of the ALMCM and HZSM5 samples was determined by the thermal desorption method (n-butylamine), in order to quantify the density and strength of the acid sites. Based on the amount of n-butylamine mols desorbed per gram of material, the density of the acid sites is quantified and the correlation to the acid strength of the sites is done based on the desorption temperature range. After the adsorption of the base in a continuous-flow fixed bed microreactor, the desorption of n-butylamine was carried out in a thermobalance. The TG/DTG curves of the ALMCM and HZSM5 samples were obtained in the range of 30 to $900{ }^{\circ} \mathrm{C}$, as shown in Figure 6 for the mesoporous and microporous materials.
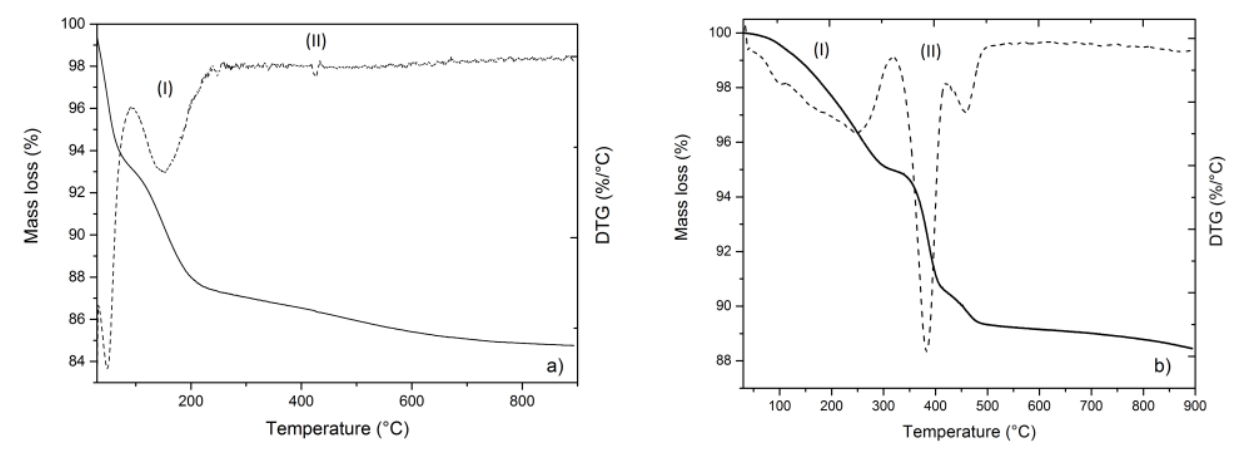

Figure 6. TG/DTG curves showing the thermal desorption of n-butylamine on mesoporous ALMCM (a) and microporous HZSM5 (b); (I) medium acid sites and (II) strong acid sites.

For both the ALMCM and HZSM5 samples, the TG/DTG curves showed three mass losses. The mass loss up to $100{ }^{\circ} \mathrm{C}$ corresponds to the output of undissolved n-butylamine. It is important to note that the initial temperature above $100{ }^{\circ} \mathrm{C}$ exceeds the boiling point (BP) of n-butylamine $\left(77^{\circ} \mathrm{C}\right)$, therefore avoiding physically adsorbed molecules [29-31]. The loss of mass relative to n-butylamine desorbed by the material is related to the acid sites. The acidity was measured considering that each mol of n-butylamine adsorbs on one mol of acid sites. The first step in the temperature range observed from $30-100{ }^{\circ} \mathrm{C}$ was attributed to physisorption and the loss of n-butylamine adsorbed onto the weak acid sites. The second step in the range $100-300{ }^{\circ} \mathrm{C}$ (medium acid sites) was attributed to desorption of the-butylamine chemisorbed and third steps considered in the ranges $300-510{ }^{\circ} \mathrm{C}$ (strong acid sites) were attributed. Based on the TG/DTG curves, the acid properties of the active sites of the samples were calculated, as shown in Table 5. 
Table 5. Acid properties of n-butylamine desorption in the ALMCM and HZSM5 samples.

\begin{tabular}{cccc}
\hline Sample & \multicolumn{3}{c}{ Concentration of Acid Sites $(\mathbf{m m o l} / \mathbf{g})$} \\
\hline & Medium-I $^{\mathbf{a}}$ & Strong-II $^{\mathbf{b}}$ & Total \\
\hline ALMCM & 0.869 & 0.043 & 0.912 \\
HZSM5 & 0.640 & 0.903 & 1.543 \\
\hline Temperature ranges: ${ }^{\mathrm{a}}\left(\mathrm{T}=100-300{ }^{\circ} \mathrm{C}\right){ }^{\mathrm{b}}\left(\mathrm{T}=300-550{ }^{\circ} \mathrm{C}\right)$.
\end{tabular}

Temperature ranges: ${ }^{\mathrm{a}}\left(\mathrm{T}=100-300^{\circ} \mathrm{C}\right) ;^{\mathrm{b}}\left(\mathrm{T}=300-550{ }^{\circ} \mathrm{C}\right)$.

Table 5 shows the concentrations of total acid sites in mmol of base per grams of catalyst. This demonstrates that the HZSM5 zeolite has a higher value than the one of the amorphous ALMCM material. The values of total acid sites are referenced in terms of $\mathrm{NH}_{3}$ and not of $\mathrm{n}$-butylamine since ammonia is one of the species resulting from the desorption of n-butylamine at the strong acid sites.

\subsection{Catalytic Test}

The catalytic tests were carried out with pure catalysts, HZSM5 zeolite and mesoporous ALMCM, as well as with mechanical mixtures between these materials in the proportions of $75 \%$ of HZSM5 and $25 \%$ of ALMCM; $50 \%$ of HZSM 5 and $50 \%$ of ALMCM; $25 \%$ of HZSM 5 and $75 \%$ of ALMCM.

Figure 7 shows the pyrograms of the products obtained in the thermal and thermo-catalytic pyrolysis of sunflower oil.

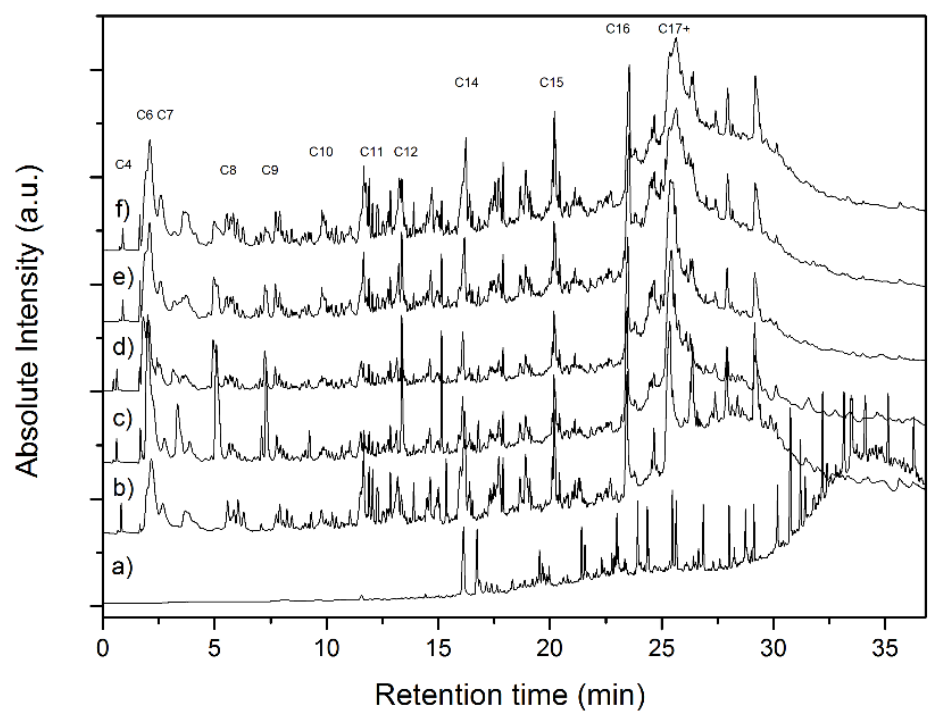

Figure 7. Pyrograms of the thermal and thermocatalytic pyrolyses of sunflower oil-(a) OILSUN; (b) OILSUN/ALMCM; (c) OILSUN/HZSM5; (d) OILSUN/75HZSM5-25ALMCM; (e) OILSUN/50HZSM5 -50ALMCM; (f) OILSUN/25HZSM5-75ALMCM.

Bio-oil obtained from the thermal pyrolysis of sunflower oil is a complex mixture of organic compounds with carbon atom number from C15 to C37 (n-alkanes e branched alkenes) and oxygenated products such as aldehydes, ketones, carboxylic acids, alcohols and esters. The most abundant chemical substances are as follows: diethyl phthalate (ester), heptadecane (n-C17), heneicosane ( $n$-C21), n-Nonadecanol-1(alcohols), 9-Octadecenamide, (Z)-, tetratriacontane ( $n$-C34), squalene (C30, branched alkenes) and hexatriacontane $(n-\mathrm{C} 37)$. As the pyrolysis temperature used in this study is low $\left(500{ }^{\circ} \mathrm{C}\right)$, the formation of carbon dioxide, carbon monoxide and aromatic, aliphatic and cyclic hydrocarbons was not observed. Generally, triglyceride pyrolysis mechanisms are difficult due to their complex chemical structures [42]. Figure 8 [42] shows the decomposition of a triglyceride reaction. 


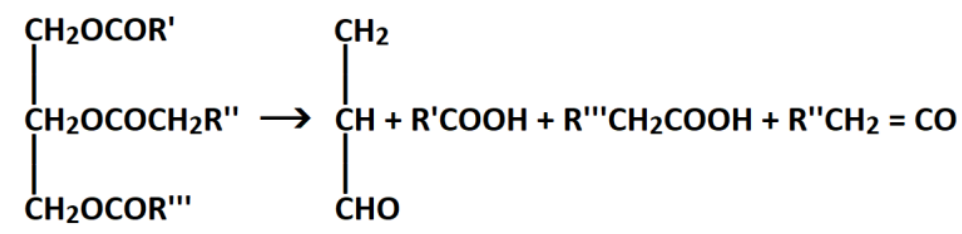

Figure 8. Decomposition of triglyceride reaction.

The data indicate a difference in the composition of the products obtained in the thermal cracking and in the thermo-catalysts. This is contrary to the idea that the presence of catalysts does not significantly alter the composition of the products of a vegetable oil pyrolysis, as reported in the literature [21,24]. On the other hand, it shows that the distribution of the products is modified by the action of the catalysts.

The intensity of the peaks related to the products with higher molar mass (greater retention time) in the pyrograms from thermo-catalytic processes is higher when compared to the same peaks in pyrograms from the thermal process.

Mesoporous materials are known for their ability to break down various high molecular weight compounds [43]. Microporous zeolites such as HY, HBeta and HZSM-5 have been studied for the cracking of several compounds for many decades because of their attributes, such as high acidity and good thermal stability [26,44]. However, due to their small pore openings, bulky molecules, such as triglycerides, face a more difficult time to enter, adding a disadvantage to their use. This led to the development of catalysts with larger pore openings, which facilitate the entry of larger molecules. These, however, lack the thermal stability suitable for catalysis because of their low acidic nature [45]. The combination of these micro and mesoporous catalytic materials results in the formation of composites that exhibit the advantages of both. The micro and mesoporous reorganization of these materials aimed at evaluating their catalytic activity based on the variety and selectivity of the products obtained through the thermo-catalytic pyrolysis reaction.

The pyrolysis of sunflower oil in the presence of catalyst (AlMCM-41 and HZSM-5) presents as a product the carbon monoxide, which provides evidence of the decarbonylation reaction. The decarboxylation and decarbonylation reaction is important for the reduction of the oxygenates product. Equations (1) and (2) show decarboxylation and decarbonylation reaction [42]:

$$
\begin{gathered}
\mathrm{R}-\mathrm{COOH} \rightarrow \mathrm{CO}_{2}+\mathrm{RH}, \\
\mathrm{R}-\mathrm{CH}_{2}-\mathrm{CH}_{2}-\mathrm{COOH} \rightarrow \mathrm{CO}+\mathrm{H}_{2} \mathrm{O}+\mathrm{R}-\mathrm{CH}=\mathrm{CH}_{2} .
\end{gathered}
$$

The products of pyrolysis of oil sunflower in the presence of the AlMCM catalyst have products with carbon atom number from C6 to C23, HZSM5 from C2 to C19 and the blend (AlMCM and HZSM5) from $\mathrm{C} 3$ to $\mathrm{C} 26$ and oxygenated products. The presence of the catalyst AlMCM directs the product to linear saturated and unsaturated hydrocarbons such as n-alkane (pentane, 2, 3-dimethyl- and heptadecane) e n-alkenes (1-hepteno, 2-octene, (E)-, 7-tetradecene and 5-eicosyne), cyclic hydrocarbons (cyclooctene, cyclopropane, 1-hexyl-2-propyl-, cis-and nonylcyclohexane) and oxygenated compounds (2-propenal, 1-Nonanol, octanoic acid and 6-octadecenoic acid). However, the catalyst HZSM5 directs the product to aromatic (benzene, toluene, o-xylene, ethylbezene and naphthalene), aliphatic (1-Hexene and 3-heptene), cyclic hydrocarbons (cyclopropane, 1-ethyl-2-propyl-, cis-and cyclohexene, 3-pentyl) and different oxygenated compounds such as fatty acids (hexanoic acid, heptanoic acid, n-decanoic acid and undecanoic acid), ketone (2-cyclohexen-1-one,4,4,5-trimethyl-), and alcohol (n-pentadecanol and 1-heptacosanol).

The analyses show that hydrocarbons make up for most of the products formed and the percentages of oxygenates decreased with the use of the catalysts. As can be seen in Table 6, the HZSM5 catalyzed pyrolysis showed a better response to the reduction of oxygenates, a result attributed to the 
Brönsted and Lewis acid sites found in the zeolite, which were effective for the deoxygenation of the oil under the pre-conditions established. In accordance with this aspect, the physical mixture with a greater percentage of HZSM5 (75HZSM5-25ALMCM) presented the same behavior in terms of deoxygenation. As the percentage of HZSM5 in the catalyst samples decreases, so does the deoxygenation potential. The deoxygenation in the sample catalyzed by ALMCM, as well as in the sample with a higher percentage of ALMCM (25HZSM5-75ALMCM) was not as satisfactory, due to the lower acidity of the material, as described previously. Nevertheless, all the samples from the thermo-catalytic processes had a lower oxygen content than those in the thermal process.

Table 6. Percentages of the products obtained in the thermal and thermo-catalytic pyrolysis.

\begin{tabular}{lcccccc}
\hline \multirow{2}{*}{ SAMPLES } & \multicolumn{2}{c}{ Classification } & \multicolumn{3}{c}{ Fractions } \\
\cline { 2 - 7 } & Hydrocarbons (\%) & Oxygenates (\%) & $\mathbf{C}_{\mathbf{2}}-\mathbf{C}_{\mathbf{4}}{ }^{\mathbf{a}}$ & $\mathbf{C}_{\mathbf{5}}-\mathbf{C}_{\mathbf{1 0}}{ }^{\mathbf{b}}$ & $\mathbf{C}_{\mathbf{1 1}}-\mathbf{C}_{\mathbf{1 6}}{ }^{\mathbf{c}}$ & $\mathbf{C}_{\mathbf{1 6}}-\mathbf{C}_{\mathbf{2 4}}{ }^{\mathbf{d}}$ \\
\hline OILSUN & 55.5 & 44.5 & 0.0 & 0.0 & 13.1 & 86.9 \\
OILSUN/ALMCM & 69.3 & 30.7 & 0.0 & 26.0 & 54.0 & 20.0 \\
OILSUN/HZSM5 & 78.8 & 21.2 & 12.0 & 46.0 & 26.0 & 16.0 \\
OILSUN/75HZSM5-25ALMCM & 77.6 & 22.4 & 4.2 & 45.8 & 37.5 & 12.5 \\
OILSUN/50HZSM5-50ALMCM & 71.7 & 28.3 & 2.6 & 44.7 & 42.2 & 10.5 \\
OILSUN/25HZSM5-75ALMCM & 58.5 & 41.5 & 0.0 & 40.0 & 48.9 & 11.1 \\
\hline${ }^{a}{ }^{a}{ }_{2}-C_{4}$ is the range of combustible gas; ${ }^{\mathrm{b}} \mathrm{C}_{5}-\mathrm{C}_{10}$ the range of gasoline; ${ }^{\mathrm{c}} \mathrm{C}_{11}-\mathrm{C}_{15}$ the range of kerosene and ${ }^{\mathrm{d}} \mathrm{C}_{16}-\mathrm{C}_{24}$ \\
the range of diesel.
\end{tabular}

Table 6 shows that the selectivity of hydrocarbons is directly related to the acid sites and to the pore diameter of the catalyst used. When assessing the thermal process, it can be seen that $87 \%$ of the products obtained are of longer chains (above 16 carbons), therefore being unsuitable for being used as fuel.

In the catalytic processes, the catalysts proved to offer better selectivity caused by the mesoporous pores. The ALMCM catalyzed pyrolysis resulted in satisfactory percentages of products with added-value for the petrochemical industry, including higher percentages in the fraction of kerosene (C11-C16).

The sample catalyzed by HZSM5 presented selectivity to light hydrocarbons in the gas range, and a posterior reduction in the range above $\mathrm{C} 16$, increasing production in the gasoline range (C5-C10).

When it comes to the samples from the physical mixtures, the products formed are similar to those obtained in the processes catalyzed by the major catalyst of the blend. Considering that in the OILSUN/25HZSM5-75ALMCM sample the ALMCM catalyst is in the majority, and is of mesoporous nature, the products formed are C5-C16 hydrocarbons. The OILSUN/75HZSM5-25ALMCM sample, on the other hand, resulted in products in the range of light hydrocarbons, with selectivity for products in the gasoline range.

The sample catalyzed by the OILSUN/50HZSM5-50ALMCM blend showed a balance between the products formed in the gasoline and diesel ranges, proving that the two catalysts acted together, providing a further reduction of the fractions above $\mathrm{C} 16$.

The good results attributed to the thermo-catalytic pyrolyzes are due to the ease of diffusion of the compounds originating from the primary cracking of sunflower oil, particularly the fatty acids, by the micro and mesoporous channels of the catalysts used. Such diffusion attenuates the fragmentation of the carbon chains of these compounds, thus making it possible to obtain hydrocarbons with a higher number of carbon atoms [46].

Another factor, which greatly influences the composition of the products, is the composition of the raw material, in this case vegetable oil. Oils and fats with a high amount of unsaturated fatty acids and with relatively small carbon chains favor the gasoline fraction with high aromatic content [21,47]. The unsaturation facilitates the carbon chain cracking process and the reactions of cyclization and subsequent aromatization [21,47]. Contrastively, those with a high content of saturated fatty acids and with large carbon chains favor diesel fractions with low aromatic content. 
Considering that the interest of this work was in obtaining biofuel with characteristics similar to those of the petroleum-derived gasoline, kerosene and diesel, it was observed that the thermo-catalytic samples from the physical mixtures 50HZSM5-50ALMCM and 25HZSM5-75ALMCM present the most adequate results to the gasoline, kerosene, diesel range, when compared to the thermocatalytic sample, ALMCM, HZSM5, 75HZSM5-25ALMCM, and the thermal pyrolysis. This indicates that the acid sites found in the HZSM5 catalyst and the pore size of the ALMCM catalyst were highly efficient for the oil cracking.

\section{Materials and Methods}

\subsection{Synthesis of the Catalysts (Al-MCM-41 and ZSM-5)}

For the synthesis of the mesoporous material Al-MCM-41, silica gel $\left(\mathrm{SiO}_{2}\right.$, Aldrich, St. Louis, MO, USA), cetyltrimethylammonium bromide (CTMAB, Vetec, Darmastadt, Hessen, Germany), sodium hydroxide ( $\mathrm{NaOH}$, Vetec, Darmastadt, Hessen, Germany), aluminum oxide $\left(\mathrm{Al}_{2} \mathrm{O}_{3}\right.$, Aldrich, St. Louis, MO, USA) and distilled water (as solvent) were used.

The hydrothermal synthesis procedure to obtain Al-MCM-4, performed according to Araújo et al. [21], consisted of the use of the above-mentioned reagents, added in stoichiometric proportions, in order to obtain a gel with the molecular composition shown in Equation (3):

$$
\text { 1CTMAB: } 2 \mathrm{NaOH}: 4 \mathrm{SiO}_{2}: 200 \mathrm{H}_{2} \mathrm{O}: \mathrm{xAl}_{2} \mathrm{O}_{3} \text {. }
$$

The value of " $\mathrm{x}$ " was adjusted so that the $\mathrm{Si} / \mathrm{Al}$ molar ratio was equal to 50 .

First, two solutions are prepared: A and B. In solution A, the surfactant cetyltrimethylammonium bromide was dissolved in distilled water. For solution $B$, the silica gel is dispersed in the sodium hydroxide in distilled water and allowed to be stirred. Solution A is added to solution B and the aluminum oxide is added while stirring for $1 \mathrm{~h}$. The resulting gel is placed in Teflon autoclaves coated with stainless steel, which is oven-proof for $24 \mathrm{~h}$ at $135^{\circ} \mathrm{C}$, forming the Al-MCM-41 material.

The material obtained was directed to the calcination process at the temperature of $450{ }^{\circ} \mathrm{C}$, with nitrogen flow for one hour, followed by a flow of synthetic air for another hour. After the completion of the procedure, the sample was named ALMCM.

The ZSM-5 zeolite was synthesized by the hydrothermal method in the absence of an organic template, as performed by Araújo et al. [26]. The following reagents were used as precursor materials: silica gel $\left(\mathrm{SiO}_{2}\right.$, Acros Organics, Morris Plains, NJ, USA), Sodium hydroxide $(\mathrm{NaOH}$, Merck, Darmastadt, Hessen, Germany), sodium aluminate $\left(\mathrm{NaAlO}_{2}\right.$, Sigma-Aldrich, St. Louis, $\mathrm{MO}$, USA) and distilled water as solvent.

The precursor materials were combined in order to obtain a molar chemical composition for the synthesis gel in the stoichiometric proportion shown in Equation (4):

$$
12 \mathrm{Na}_{2} \mathrm{O}: 2 \mathrm{Al}_{2} \mathrm{O}_{3}: 100 \mathrm{SiO}_{2}: 2500 \mathrm{H}_{2} \mathrm{O} \text {. }
$$

Vigorous stirring, together with heating at the temperature of $70{ }^{\circ} \mathrm{C}$, play an important role in the final product obtained. This agitation is responsible for the homogenization of the reaction mixture becoming the agent responsible for the crystallization process of the ZSM-5 zeolite without an organic template, thus providing an increase in the nucleation rate [27].

ZSM- 5 zeolite was obtained in its sodium form (Na-ZSM-5) through the synthesis. In the dry solid state, the $\mathrm{Na}^{+}$were replaced by $\mathrm{NH}_{4}{ }^{+}$cations in a refluxing system with a 1 molar solution of Ammonium $\left(\mathrm{NH}_{4} \mathrm{Cl}\right)$. Next, the sample was directed to the calcination process at $300{ }^{\circ} \mathrm{C}$ under nitrogen flow for $3 \mathrm{~h}$. Through the thermal treatment, the $\mathrm{NH}_{4}{ }^{+}$cations decompose into $\mathrm{NH}_{3(\mathrm{~g})}$, leaving an $\mathrm{H}+$ proton bound to the structure, transforming it into its protonated form (H-ZSM-5). The material obtained after the completion of the ion exchange process was named HZSM5 [29]. 


\subsection{Characterization of the Materials Obtained}

The synthesized samples were characterized by thermal analysis, X-ray diffraction, Fourier transform infrared spectroscopy, nitrogen adsorption and determination of the surface acidity.

The thermogravimetric analyzer (TG/DTG) of the mesoporous material ALMCM (calcined and non-calcined) were performed in 851 Mettler Toledo equipment (Polaris Parkway, Columbus, $\mathrm{OH}$, USA), with a heating rate of $10{ }^{\circ} \mathrm{C} \mathrm{min}^{-1}$, starting from ambient temperature $\left(\sim 30^{\circ} \mathrm{C}\right)$ up to $900{ }^{\circ} \mathrm{C}$, using a nitrogen atmosphere with a flow rate of $25 \mathrm{~mL} \mathrm{mim}^{-1}$, alumina crucibles and approximately $20 \mathrm{mg}$ of sample.

The synthesized samples were characterized with XRD 6000 SHIMADZU equipment (Chiyoda-ku, Tokyo, Japan), using a $\mathrm{CuK} \alpha$ radiation source and a nickel filter with a $30 \mathrm{kV}$ and $30 \mathrm{~mA}$ tube voltage, respectively. The data were collected using the powder method in the $2 \theta$ range $=1$ to $10^{\circ} \mathrm{C}$ for the ALMCM and 5 to $80^{\circ} \mathrm{C}$ for the HZSM5, with a scanning speed of $2 \mathrm{~min}^{-1}$.

The infrared absorption spectroscopy analyses were performed in a Fourier transform infrared spectrometer (Bomem MB-104 FT-IR), using potassium bromide $(\mathrm{KBr})$ as a dispersing agent $(0.1 \mathrm{~g}$ of $\mathrm{KBr}$ for each $0.005 \mathrm{~g}$ of sample) for the formation of the tablet. The FTIR spectra correspond to the sum of 64 scans at a spectral resolution of $4 \mathrm{~cm}^{-1}$ and scan $4000-400 \mathrm{~cm}^{-1}$.

The analyses of the nitrogen adsorption and desorption isotherms of the calcined samples were performed on Quantachrome Nova 2000 equipment (Gilroy, CA, USA), where about $100 \mathrm{mg}$ of the samples were pretreated at $300{ }^{\circ} \mathrm{C}$ for $3 \mathrm{~h}$ under vacuum and then subjected to nitrogen adsorption at $77 \mathrm{~K}$. The isotherms were obtained in a P/Po range varying from 0.01 to 0.95 .

The acidity measurements of the synthesized micro and mesoporous materials were determined by base adsorption followed by desorption through temperature increase. The base used as the probe molecule was n-butylamine, the procedure for saturating the acid sites of the materials with n-butylamine consisted of subjecting the calcined sample under an activation at a temperature of $400{ }^{\circ} \mathrm{C}$ with a flow rate of $\mathrm{N}_{2}$ flow of $100 \mathrm{~mL} / \mathrm{min}$ for $2 \mathrm{~h}$. After this period, the temperature was reduced to $95^{\circ} \mathrm{C}$ and the n-butylamine vapors were continuously directed to the samples by the $\mathrm{N}_{2}$ flow for $1 \mathrm{~h}$ for complete saturation of the acid sites present in the materials.

The determination of the amount of the base retained in each temperature range was performed in a thermogravimetric analyzer at a heating rate of $10{ }^{\circ} \mathrm{C} \mathrm{min}^{-1}$, starting from ambient temperature $\left(\sim 30^{\circ} \mathrm{C}\right)$ up to $900{ }^{\circ} \mathrm{C}$, under a nitrogen flow rate of $25 \mathrm{~mL} \mathrm{~min}^{-1}$. The acidity of the samples was determined as a function of the amount of thermally desorbed n-butylamine $[29,30]$. The total acidity $\left(A_{\text {total }}\right)$ is calculated through the sum of the acid sites $\left(\mathrm{N}_{\text {sites }}\right)$ chemisorbed by $\mathrm{n}$-butylamine in $\mathrm{mmol} / \mathrm{g}$, according to Equation (5):

$$
\mathrm{A}_{\text {total }}=\Sigma N_{\text {sites }}=\left(m_{n \text {-butylamine }} / M M_{n \text {-butylamine }} \cdot m_{\text {sample }}\right) .
$$

\subsection{Catalytic Test}

The catalytic test was carried out in order to evaluate the activity of the catalysts in the pyrolysis of sunflower oil (OILSUN). In addition to the pure synthesized samples, physical mixtures were made with the catalysts obtained. These are their proportions: 75\% wt HZSM5/25\% wt ALMCM (75HZSM5-25ALMCM), 50\% wt HZSM5/50\% wt ALMCM (50HZSM5-50ALMCM) and 25\% wt HZSM5/75\% wt of ALMCM (25HZSM5-75ALMCM).

The sunflower oil used does not contain any additives, passed only by the process of refinement. It was purchased from the company "Campestre Indústria e Comércio de Óleos Vegetais LTDA".

Based on tests starting with gas chromatography, the composition of the fatty acids present in sunflower oil can be verified. The major fatty acids are an average of $16-24 \%$ oleic (C18:1) and $65-72 \%$ linoleic acid (C18:2) [28].

For thermocatalytic, $10 \%$ by mass of catalyst was added to the sunflower oil, mixing physically until homogenization. 
The thermal and thermo-catalytic pyrolyzes of the sunflower oil were performed in a Frontier PY-2020iS pyrolyzer (Koriyama, Fukushina, Japan), coupled to a Shimadzu QP2010 GC/MS (Kyoto, Japan). The samples were placed in a stainless-steel crucible (Koriyama, Fukushina, Japan) with a volume of $50 \mu \mathrm{L}$. The analyzes were performed under a helium gas atmosphere with a flow rate of $3.0 \mathrm{~mL} \mathrm{~min}-1$, a pyrolyzer temperature set at $500^{\circ} \mathrm{C}$, pyrolysis time of $1 \mathrm{~min}$, split ratio of 200:1 and pyrolyzer-GC interface temperature of $250{ }^{\circ} \mathrm{C}$ (injector temperature). The pyrolysis products were separated in an RTX-1 PONA capillary column (100\% dimethyl polysiloxane) (Bellefonte, PA, USA) with a length of $100 \mathrm{~m}$, diameter of $0.25 \mathrm{~mm}$ and stationary phase thickness of $0.5 \mathrm{um}$. The column pressure was kept at $116.7 \mathrm{kPa}$, with a flow rate of $2.20 \mathrm{~mL} \mathrm{~min}^{-1}$ and linear velocity of $53.2 \mathrm{~cm} / \mathrm{s}$. The chromatography oven was programmed as follows: temperature of $30^{\circ} \mathrm{C}$ for $5 \mathrm{~min}$, followed by heating to $320^{\circ} \mathrm{C}$ with a heating rate of $10^{\circ} \mathrm{C} \mathrm{min}^{-1}$. The programmed time was $37 \mathrm{~min}$. The GC/MS interface temperature was kept at $250^{\circ} \mathrm{C}$. The detection range of the mass spectrometer was maintained between 20 and $600 \mathrm{~m} / z$; the scanning interval was $0.50 \mathrm{~s}$, and the scanning speed was $1250 \mathrm{uma} / \mathrm{s}$.

The various constituents present in the products of the sunflower oil pyrolysis were identified through the NIST (National Institute of Standards of Technology) library database software coupled to the GC/MS analysis system. The products were quantified by the standardization method (\% area).

With the data obtained through the library database, the fractionation of the interest range was done based on the \% area of the peaks found. These results are illustrated in Table 6 .

\section{Conclusions}

Based on the characterization techniques used to evaluate the properties of the mesoporous catalyst $\mathrm{ALMCM}$, with ratio $\mathrm{Si} / \mathrm{Al}=50$, the formation of the one-dimensional hexagonal structure can be confirmed by X-ray diffraction. The nitrogen adsorption proved that the material presents a satisfactory surface area for catalysis and the measurement of surface acidity demonstrated the presence of moderate acid sites.

The HZSM5 zeolite was obtained by hydrothermal synthesis in the total absence of organic template. By analyzing the X-ray diffraction results, the formation of the MFI pore structure was observed, with characteristic peaks in the range of $7-50^{\circ}(2 \theta)$. The nitrogen adsorption demonstrated the compatibility of the surface area, as well as of the other textural properties, with patterns synthesized via structural template. The proposed route of synthesis is feasible, reducing the environmental impact generated and the costs associated with the equivalent commercial material.

The HZSM5 catalyzed pyrolysis presented a better response to the reduction of oxygenates, a result attributed to the Brönsted and Lewis acid sites found in the zeolite, which were efficient for the deoxygenation of the oil under the pre-established conditions.

With the application in catalytic tests for the pyrolysis reaction, a relation between the properties of the materials and the range of hydrocarbons obtained is observed. The products of pyrolysis of oil sunflower in the presence of the AlMCM catalyst have products with carbon atom number from $\mathrm{C} 6$ to C23, HZSM 5 from C2 to C19 and the blend (AlMCM and HZSM5) from C3 to C26 and oxygenated products. The HZSM5 material was more efficient at obtaining short chain hydrocarbons (C5-C10), whereas ALMCM was more efficient at obtaining middle chain hydrocarbons (C11-C16). This is due to their pore sizes.

The products obtained through the thermo-catalytic pyrolysis of the mechanical mixtures of the catalysts are close to the products catalyzed by the majority samples in their pure form. It is important to note that the 50HZSM5-50ALMCM material presented a balance between the products formed in the gasoline, kerosene and diesel ranges. This is evidence that the two catalysts act together, providing a greater reduction of the fractions above $\mathrm{C} 16$.

Author Contributions: A.M.M.A conceived and designed the experiments; G.S.M.Q and D.O.M. performed the experiments; A.D.G. and L.D.S analyzed the data; V.J.F.J. and A.S.A contributed reagents/materials/analysis tools; A.M.M.A wrote the paper. 
Acknowledgments: All sources of funding of the study should be disclosed. Please clearly indicate grants that you have received in support of your research work. Clearly state if you received funds for covering the costs to publish in open access.

Conflicts of Interest: The authors declare no conflict of interest.

\section{References and Note}

1. Han, Y.; Stankivikj, F.; Garcia-Perez, M. Co-hydrotreatment of tire pyrolysis oil and vegetable oil for the production of transportation fuels. Fuel Process. Technol. 2017, 159, 328-339. [CrossRef]

2. Szklo, A.S.; Machado, G.; Schaeffer, R.; Simões, A.F.; Mariano, J.B. Placing Brazil's heavy acid oils on international markets. Energy Policy 2006, 36, 692-705. [CrossRef]

3. Jacobson, K.; Maheria, K.C.; Dalai, A.K. Bio-oil valorization: A review. Renew. Sustain. Energy Rev. 2013, 23, 91-106. [CrossRef]

4. Wu, L.; Guo, S.; Wang, C.; Yang, Z. Production of alkanes $\left(C_{7}-C_{29}\right)$ from different part of poplar tree via direct deoxy-liquefaction. Bioresour. Technol. 2009, 100, 2069-2076. [CrossRef] [PubMed]

5. Qiang, L.; Wen-Zhi, L.; Xi-Feng, Z. Overview of fuel properties of biomass fast pyrolysis oils. Energy Convers. Manag. 2009, 50, 1376-1383.

6. Demirbas, A. Biomass resource facilities and biomass conversion processing for fuels and chemicals. Energy Convers. Manag. 2001, 42, 1357-1378. [CrossRef]

7. Yaman, S. Pyrolysis of biomass to produce fuels and chemical feedstocks. Energy Convers. Manag. 2004, 45, 651-671. [CrossRef]

8. Demirbas, A.; Arin, G. An overview of biomass pyrolysis. Energy Sources 2002, 24, 471-482. [CrossRef]

9. Bridgwater, A.V. Catalysis in thermal biomass conversion. Appl. Catal. A Gen. 1994, 116, 5-47. [CrossRef]

10. Bridgwater, A.V.; Peacoke, G.V.C. Fast pyrolysis processes for biomass. Renew. Sustain. Energy Rev. 2000, 4, 1-73. [CrossRef]

11. Mohan, D.; Pittman, C.U.; Steele, P.H. Pyrolysis of wood/biomass for bio-oil: A critical review. Energy Fuels 2006, 20, 848-889. [CrossRef]

12. Domínguez-Barroso, M.V.; Herrera, C.; Larrubia, M.A.; Alemany, L.J. Diesel oil-like hydrocarbn production from vegetable oil in a single process over $\mathrm{Pt}-\mathrm{Ni} / \mathrm{Al}_{2} \mathrm{O}_{3}$ and $\mathrm{Pd} / \mathrm{C}$ combined catalysts. Fuel Process. Technol. 2016, 148, 110-116. [CrossRef]

13. Silvério, F.O.; Barbosa, L.C.A. Pirólise como técnica analítica. Quím. Nova 2008, 31, 1543-1552. [CrossRef]

14. Zhang, L.; Hu, G. Supply chain design and operational planning models for biomass to drop-in fuel production. Biomass Bioenergy 2013, 58, 238-250. [CrossRef]

15. Shouyun, C.; Wei, L.; Julson, J.; Muthukumarappan, K.; Kharel, P.R.; Boakye, E. Hidrocarbon bio-oil production from pyrolysis bio-oil using non-sulfide $\mathrm{Ni}-\mathrm{Zn} / \mathrm{Al}_{2} \mathrm{O}_{3}$ catalyst. Fuel Process. Technol. 2017, $162,78-86$.

16. Koike, N.; Hosokai, S.; Takagaki, A.; Nishimura, S.; Kikuchi, R.; Ebitani, K.; Suzuki, Y.; Oyama, S.T. Upgrading of pyrolysis bio-oil using nickel phoshide catalysts. J. Catal. 2016, 333, 115-126. [CrossRef]

17. Stefanidis, S.D.; Karakoulia, S.A.; Kalogiannis, K.G.; Iliopoulouil, E.F.; Delimitis, A.; Yannoulakis, H.; Zampetakis, T.; Lappas, A.A.; Triantafyllidis, K.S. Natural magnesium oxide (MgO) catalysts: A cost-effective sustainable alternative to acid zeolites for the in situ upgrading of biomass fast pyrolysis oil. Appl. Catal. B Environ. 2016, 196, 155-174. [CrossRef]

18. Choi, S.J.; Park, S.H.; Jeon, J.; Lee, I.G.; Ryu, C.; Suh, D.J.; Park, Y. Catalytic conversion of particle board over microporous catalysts. Renew. Energy 2013, 54, 105-110. [CrossRef]

19. Wang, Y.; He, T.; Liu, K.; Wu, J.; Fang, Y. From biomass to advanced bio-fuel by catalytic pyrolysis/hidro-processing: Hydrodeoxygenation of bio-oil derived from biomass catalytic pyrolysis. Bioresour. Technol. 2012, 108, 280-284. [CrossRef] [PubMed]

20. Ramli, A.; Razak, R.A. Analysis of the organic liquid produced from catalytic cracking of crude palm oil in the presence of alumina supported catalysts. AIP Conf. Proc. 2012, 1482, 643-648.

21. Araújo, A.M.M.; Lima, R.O.; Gondim, A.D.; Diniz, J.; Souza, L.D.; Araujo, A.S. Thermal and catalytic pyrolysis of sunflower oil using AlMCM-41. Renew. Energy 2017, 101, 900-906. [CrossRef] 
22. Mâncio, A.A.; Costa, K.M.B.; Ferreira, C.C.; Santos, M.C.; Lhamas, D.E.L.; da Mota, S.A.P.; Leão, R.A.C.; de Souza, R.O.M.A.; Araújo, M.E.; Borges, L.E.P.; et al. Process analysis of physicochemical properties and chemical composition of organic liquid products obtained by thermochemical conversion of palm oil. J. Anal. Appl. Pyrolysis 2017, 123, 284-295. [CrossRef]

23. Hu, X.; Gunawan, R.; Mourant, D.; Hasan, M.D.M.; Wu, L.; Song, Y.; Lievens, C.; Li, C.Z. Upgrading of bio-oil via acid-catalyzed reactions in alcohols-A mini review. Fuel Process. Technol. 2017, 155, 2-19. [CrossRef]

24. Kubicka, D.; Kaluza, L. Deoxygenation of vegetable oils over sulfide Ni, Mo and NiMo catalysts. Appl. Catal. A Gen. 2010, 372, 199-208. [CrossRef]

25. Beck, J.S.; Vartuli, J.G.; Roth, W.J.; Leonowicz, M.E.; Kresge, C.T.; Schmitt, K.D.; Chu, C.T.W.; Olson, D.H.; Sheppard, E.W.; Mcculen, S.B.; et al. A new family of mesoporous molecular-sieves prepared with liquid-crystal templates. J. Am. Chem. Soc. 1992, 114, 10834-10843. [CrossRef]

26. Araújo, A.M.M.; Figueiredo, A.L.; Gondim, A.D.; Guedes, A.P.M.A.; Di Souza, L.; de Araujo, A.S. Thermal and catalytic pyrolysis of vacum gas oil using HZSM-5: TG and PY-GC/MS. Pet. Sci. Technol. 2016, 34, 247-252. [CrossRef]

27. Costa, M.J.F.; Araujo, A.S. Zeólitas Sintetizadas na Ausência Total de Direcionador Orgânico e Respectivo Processo de Síntese. Rev. Propr. Ind. 2010, 2083, 76.

28. EMBRAPA, Agroenergia, Biorrefinarias 2012. Acesso em 05 de maio de 2017.

29. Zhao, X.S.; Lu, G.Q.; Millar, G.J. Advances in Mesoporous Molecular Sieve MCM-41. Ind. Eng. Chem. Res. 1996, 35, 2075-2090. [CrossRef]

30. Araujo, A.S.; Jaroniec, M. Synthesis and properties of lanthanide incorporated mesoporous molecular sieves. J. Colloid Interface Sci. 1999, 218, 462-467. [CrossRef] [PubMed]

31. Silva, A.O.S. Síntese e Caracterização de Catalisadores de Ferro e Cobalto Suportados nas Zeólitas HZSM-12 e HZSM-5 para a Conversão de gás de Síntese em Hidrocarbonetos. Tese (Doutorado em Engenharia Química) Programa de Pós-Graduação em Engenharia Química, Programa de Recursos Humanos da Agência Nacional do petróleo para o Setor de Petróleo e Gás-PRH/ANP-14, Universidade Federal do Rio Grande do Norte, Natal, Brazil, 2004.

32. Sang, S.; Chang, F.; Liu, Z.; He, C.; He, Y.; Xu, L. Difference of ZSM-5 zeolites synthesized with various templates. Catal. Today 2004, 93, 729-734. [CrossRef]

33. Kruk, M.; Jaroniec, M.; Sayari, A. Adsorption study of surface properties of MCM-41 materials with different pore sizes. J. Phys. Chem. 1997, 101, 583-589. [CrossRef]

34. Maciel, S.T.A.; Wisniewski, A.; Souza, M.J.B. Use of micropyrolysis and Tg to sudy the termal catalytic conversion of onshore crude oil using the zeolite catalysts type $\mathrm{Y}$ and ferrite. J. Therm. Anal. Calorim. 2015, 122, 369-377. [CrossRef]

35. Zholobenko, V.L.; Holmes, S.M.; Cundy, C.S.; Dwyer, J. Synthesis of MCM-41 materials: In situ FTIR study. Microporous Mater. 1997, 11, 83-86. [CrossRef]

36. Silverstein, R.M.; Webster, F.X.; Kiemle, D.J. Identificação Espectrométrica de Compostos Orgânicos, 7th ed.; LTC: Rio de Janeiro, Brazil, 2007; ISBN 9788521615217.

37. Narayanan, S.; Sultan, A.; Le, Q.T.; Aurox, A. A comparative and multitechnical approach to the acid character of template and non-template ZSM-5 zeolites. Appl. Catal. A Gen. 1998, 168, 373-384. [CrossRef]

38. Han, W.; Jia, Y.; Xiong, G.; Yang, W. Synthesis of hierarchical porous materials with ZSM-5 structures via template-free sol-gel method. Sci. Technol. Adv. Mater. 2007, 8, 101-105. [CrossRef]

39. Sing, K.S.W.; Everett, D.H.; Haul, R.A.W.; Moscou, L.; Pierotti, R.A.; Rouquérol, J.; Siemieniewska, T. Reporting physisorption data for gas/solid systems with special reference to the determination of surface area and porosity. Pure Appl. Chem. 1985, 57, 603-619. [CrossRef]

40. Biligetu, T.; Wang, Y.; Nishitoba, T.; Otomo, R.; Park, S.; Mochizuki, H.; Kondo, J.N.; Tatsumi, T.; Yokoi, T. Al distribution and catalytic performance of ZSM-5 zeolites synthesized with various alcohols. J. Catal. 2017, 353, 1-10. [CrossRef]

41. Coriolano, A.C.F.; Silva, C.G.C.; Costa, M.J.F.; Pergher, S.B.C.; Caldeira, V.P.S.; Araujo, A.S. Development of HZSM-5/AlMCM-41 hybrid micro-mesoporous material and application for pyrolysis of vacuum gas oil. Microporous Mesoporous Mater. 2013, 172, 206-212. [CrossRef]

42. Kraiem, T.; Hassen, A.B.; Belayouni, H.; Jeguirim, M. Production and characterization of bio-oil from the pyrolysis of waste frying oil. Environ. Sci. Pollut. Res. 2017, 24, 9951-9961. [CrossRef] [PubMed] 
43. Kloestra, K.R.; Zandbergen, H.W.; Jansen, J.C.; Bekkum, H.V. Overgrowth of mesoporous MCM-41 on faujasite. Microporous Mater. 1996, 6, 287-293. [CrossRef]

44. Adjane, J.D.; Bakhshi, N.N. Production of hydrocarbons by catalytic upgrading of a fast pyrolysis bio-oil. Part I: Conversion over various catalysts. Fuel Process. Technol. 1995, 45, 185-202.

45. Chew, T.L.; Bhatia, S. Catalytic processes towards the production of biofuels in a palm oil and oil palm biomass-based biorefinery. Bioresour. Technol. 2008, 99, 7911-7922. [CrossRef] [PubMed]

46. Santos, C.D.; Bofim, L.M.; Motta, J.A.S.; Rodrigues, G.; Nascimento, A.R.; Araujo, A.S.; Pedrosa, A.M.G.; Souza, M.J.B. Estudo da pirólise de óleo de soja sobre peneiras moleculares micro e mesoporosas. Sci. Plena 2009, 5, 1-14.

47. Idem, R.O.; Bakhshi, N.N. Kinetic modeling of the production of hydrogen from the metanol-steam reforming process over Mn-promoted coprecipitated Cu-Al catalyst. Chem. Eng. Sci. 1996, 51, 3697-3708. [CrossRef]

(c) 2018 by the authors. Licensee MDPI, Basel, Switzerland. This article is an open access article distributed under the terms and conditions of the Creative Commons Attribution (CC BY) license (http:/ / creativecommons.org/licenses/by/4.0/). 